\title{
Research on Application of Micro-curriculum Design and Teaching Structure in Perspective of Lifelong Education
}

\author{
Gang Chen ${ }^{1, a}$ \\ ${ }^{1}$ School of Information Management and Engineering, \\ Shanghai University of Finance and Economics \\ Shanghai, 200433 China \\ aemail: gladychen@126.com,
}

Keywords: micro curriculum design and teaching structure; Lifelong education; Learner characteristics analysis; Learning content analysis; Content design

\begin{abstract}
Micro curriculum design and teaching architecture including design preparation stage, design and development stage, feedback stage. The design preparation stage includes: learner characteristics analysis, learning content analysis and building knowledge unit. Design and development phase includes: content design, instructional design, structure design, interface design, script design, video recording and communication between teachers and students. The feedback stage includes the evaluation of the teacher summary and the micro curriculum.
\end{abstract}

\section{Introduction}

Lifelong education adapts to the "space virtualization" and "time fragmentation" of the learning society. It is a comprehensive and personalized experience system for students in the mixed learning environment at any times, anywhere, with the need to obtain a comprehensive and personalized development. [1] Micro courses include teaching activities related to teaching plans, courseware, exercises, feedback and reflection, and other auxiliary teaching materials Video is one of the most important learning resources for learners. Lesson plan is the starting point of micro curriculum design, but also guide the whole micro teaching activities. Lesson plan is the starting point of micro curriculum design, but also guide the whole micro teaching activities. Courseware refers to other multimedia resources and materials used in teaching activities. Exercises are based on the micro curriculum content design of the test questions, the form can be varied, focusing on the depth of students thinking. [2] Feedback is the study of the current content of the summary of the evaluation, but also the teacher's comments on the learner, is an extension of the exercise link. Reflection is the teaching experience of teachers in the practice of micro teaching practice and teaching experience, to guide the development of follow-up courses. Micro curriculum should be rooted in the reality of the classroom. It needs to pay attention to the teaching design, the introduction of the curriculum, the core concept of the lecture, the demonstration of the process of inquiry and after class exercises, etc. It should analyze the needs of students, combined with the demand of teaching tasks. It should determine the content of learning, and to solve the micro curriculum resources.

\section{Misunderstanding of Micro curriculum design}

There will be some misunderstandings in the process of micro curriculum design and production practice.

The micro curriculum should not be regarded as a technology development process. It is believed that the micro curriculum is made only by educational and technical personnel. Micro courses do indeed need technical support, particularly in support of education technology, but micro course from the root, it is a type of curriculum resources. Therefore, the micro courses is not only a technology development process, is a fine under the support of advanced education idea a product of the meaning of design education, is a highly creative work, making micro course is the key factor 
is, the man is a teacher.

The micro curriculum should not be as the choice of classroom teaching. Traditional a whole section lesson interception of a lesson fragment actually, micro class, in essence, it is a kind of course. The original intention is to provide resources for independent study for the students. The content is highly concentrated and relatively complete and systematic. An interception miniature video, from the integrity, it lacks the micro courses required supporting auxiliary teaching resources, even as key components of micro course -- video teaching, whether it is a lesson piece, micro video and mini lectures, if time is short, but content is not focused, without considering the cognitive and learning rules, you can't be in the true sense of the micro video.

The focus of the production of micro curriculum on the micro curriculum production technology, especially the shooting and post editing, results in the production of micro curriculum in the late time and energy to invest too much. Making real micro course, micro course content of the theme selection, teaching design, teaching strategy, teaching implementation is the core link, ignoring the core link, micro curriculum teaching and learning effects will be poor.

\section{Outline of micro curriculum design and teaching structure}

The micro curriculum is a complete course. There is a complete set of teaching design about it. Teaching support services should be an integral part of it. Teaching support services assume the functions of online counseling. So it can avoid that learning content is too fragmented caused by students lost.[3] Teaching support services to enhance the use of online synchronous, asynchronous communication tools between teachers and students, so that students can learn everywhere, making the class of formal learning and extra-curricular learning unified, continuous.

After the prototype of the micro curriculum design, it needs to be judged by teachers and students, and constantly improve the micro curriculum in the exchange. Micro curriculum and other micro curriculum resources to establish a network, and with the teaching needs and the development of the environment and enrich the network structure, such learning resources and classroom teaching will be full of vitality. [4] The realization of the dynamic generation of learning resources should be reflected through the evaluation and feedback of teachers and students. Evaluation and feedback can provide suggestions for the analysis and design of micro curriculum.

Micro curriculum design and teaching architecture is including design preparation stage, design and development stage and feedback stage. As shown in figure 1:

\section{Design preparation stage of Micro curriculum}

The design preparation stage of Micro curriculum includes: learner characteristics analysis, learning content analysis and building knowledge unit.

Learner characteristics analysis

Due to the complexity of learning materials and learners' current knowledge level, it should be carefully analyzed the characteristics of learners, learning ability and learning style, and then provide the corresponding micro curriculum teaching arrangements. [5]

Learning content analysis

The reasonable choice of teaching content is the first step in the development of micro curriculum, and it is also a key step. It reflects the micro curriculum is about what content, related to the core value of micro curriculum. The formation of the selected topic is also a process of research, which requires not only the accumulation of teaching experience, but also the insight and foresight of scientific research. The topic of micro curriculum should be concise, teaching objectives should be clear, targeted, whether it is for the knowledge point or method can both have a learning task.

Building knowledge unit

Knowledge unit is the specific knowledge point of micro curriculum. Building knowledge unit is the most important part in the design and development of micro curriculum. The following aspects should be paid attention to in the process of building a knowledge unit. The first thing is to sort out the relationship between the teaching objectives and the knowledge unit. [6] As the knowledge unit 
contained in the micro curriculum is small, it is decided that the knowledge unit can't carry too many, too large, too complex teaching objectives. Secondly, based on the analysis of the teaching objectives, considering the capacity of the micro curriculum and the difficulty of knowledge points, it will be decomposed into the target of individual knowledge units. We should consider whether to add additional knowledge unit, whether to set up independent knowledge unit. If the micro course is just an auxiliary classroom teaching supplement, it is not necessary to incorporate all the knowledge units into the micro curriculum. If the micro curriculum is an open curriculum teaching supplement, it is necessary to add some other knowledge points.

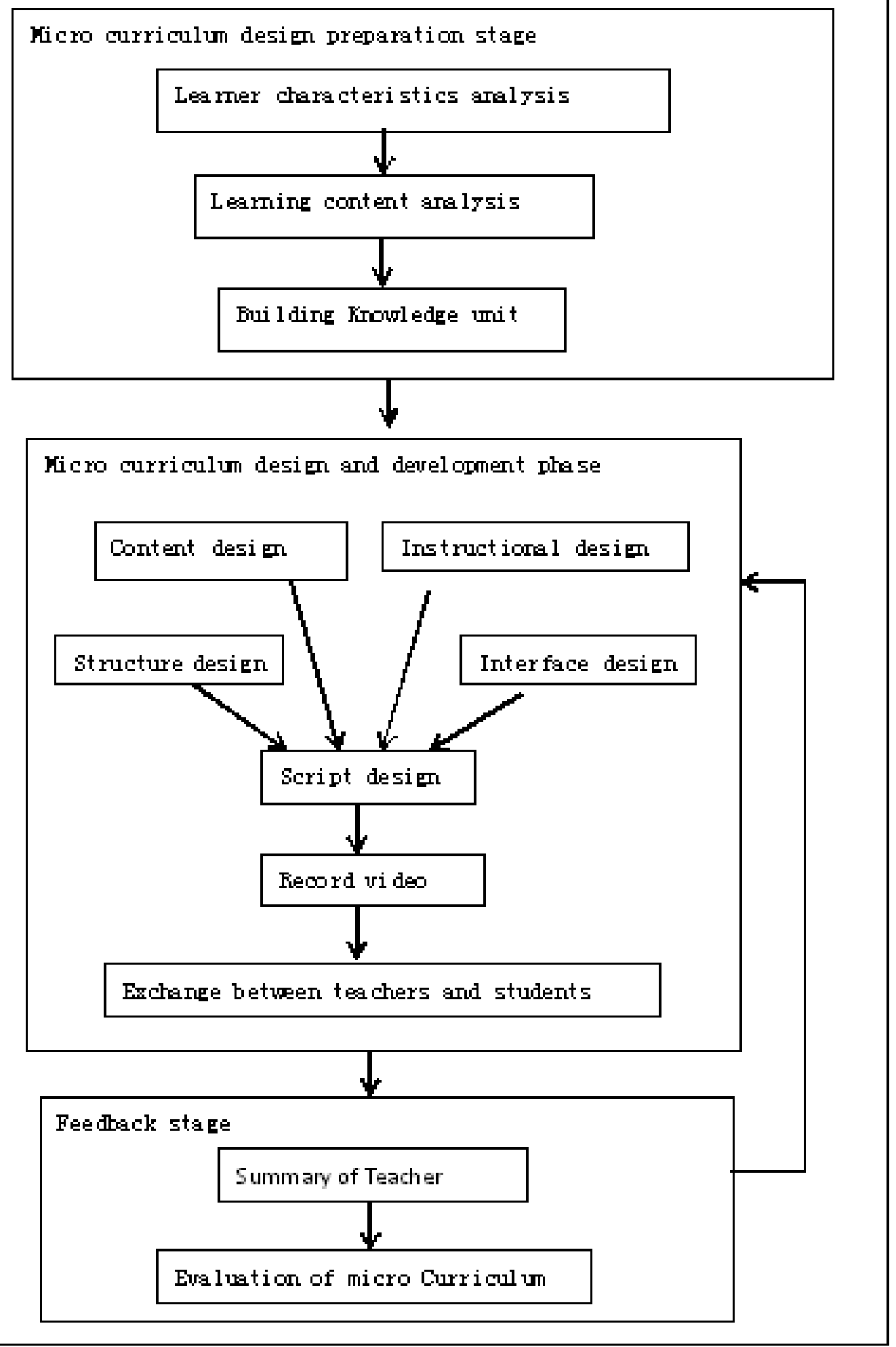

Fig.1. Micro curriculum design and teaching structure 


\section{Design and development phase of Micro curriculum}

Design and development phase includes: content design, instructional design, structure design, interface design, script design, video recording and communication between teachers and students.

Content design

Content design is the first problem is how to make a reasonable knowledge of the cutting, that is, the knowledge point of the micro processing. Theme, not the pursuit of the content of the system coverage, but based on the micro standard curriculum and minimal granularity principle, select the dapper and includes the knowledge points materials should be in the content selection. The contents of each block can independently bear complete knowledge points, which can be, but do not need to loose combination of its adjacent knowledge points.

Instructional design

Instructional design is the use of the viewpoints and methods of system science, analysis of the content and object of teaching, teaching objectives identified, establishment of teaching content knowledge structure, selection and design of appropriate strategies and media and design exercises and learning evaluation process.[7] The choice of teaching media is an important part of teaching design. Students of different age stages of the cognitive characteristics have very big difference, in the selection and design of teaching media, we must fully consider the characteristics of students of different age stages of cognition, can never apply a fixed and rigid mode.

Structure design

The structure of micro curriculum reflects the specific teaching thought, learning theory and teaching content. Different teaching content, according to the teaching thought, the learning theory is different, often the structure of the micro course is also different. Structure design is to learners show a variety of teaching information; for diagnosis, evaluation, treatment and guide various kinds of information on the process of learning, as well as the realization of learning process control strategies and learning process control information.

Interface design

Three basic principles of interface design: first, the principle of interest oriented; second, the principle of simplification; third, the principle of unified style. Interesting refers to the micro curriculum makers should be based on the knowledge of the content of the different, in every link in the comprehensive use of audio-visual means and editing techniques, the boring complex learning content to do art, fun of processing. The principle of simplification is that in just a few minutes, the requirements of the presentation of the interface is simple, do not have too many irrelevant. The principle of unified style, the requirements of the interface design should make people look after the overall sense of consistency.

\section{Script design}

There are two kinds of micro course recording methods, one is to record screen. The other is a shot. Recording screen is recorded with the recording screen software to record the teaching process. When recording teachers only need to carefully prepare the courseware on the screen to demonstrate, select a good recording of video and audio format, the software will be the entire recording of the teacher's screen operation and explanation. The whole process is simple and easy to operate.

Communication between teachers and students

The communication between teachers and students is any teaching activity indispensable a link, while relying on the communication network of micro course just can achieve is more convenient and powerful interactive communication between teachers and students. The most effective way is to design the interactive $\mathrm{Q} \& \mathrm{~A}$, which can make full use of the network platform to design the question answering system, and strengthen the interaction between teachers and students.

\section{Feedback stage}

The feedback stage includes the evaluation of the teacher summary and the micro curriculum. The task of micro curriculum evaluation is to evaluate students' independent learning effect, 
classroom teaching effect and the ability of teachers' micro teaching. Micro curriculum evaluation can be a variety of ways, such as testing practice, student self-assessment, teacher evaluation, student feedback, etc. Micro curriculum evaluation on the one hand, let teachers and students understand the teaching concept of micro teaching method, on the other hand to help teachers and students found in the teaching practice of the deficiencies, to carry out teaching reflection. The design of micro curriculum evaluation should help to improve students' ability of mastering and learning knowledge, and it is helpful to improve the ability of micro video production and the management ability of micro curriculum. By reviewing the process of reviewing the teaching process, the teacher adds new ideas or changes the part that he thinks is not satisfied, in order to achieve the effect of improving. It helps to improve the quality of micro courses.

\section{Conclusion}

The application of micro curriculum to lifelong education will lead to fundamental changes in educational philosophy, educational content, educational methods and means. As a kind of new learning experience, micro curriculum learning may become a normal way of teaching in school education. Micro curriculum dissemination platform will gradually migrate from the PC to the smart phone as the representative of the mobile device terminal, to achieve anytime, anywhere ubiquitous learning resources to provide quality.

\section{References}

[1] Chen Gang, Data center management plan in cloud computing environment. In: 3rd International Conference on Information Management, Innovation Management and Industrial Engineering, ICIII, vol. 4, pp. 393-396, 2010

[2] Sun Zhong, \& Ma Yuhui The effect of video research of classroom teaching: Research on the new ways of group learning channel for teachers in the web era ( in Chinese) [ J . Open Educational Research, 18 (2): 80 - 85.2012

[3] Chen Gang, Decision-making model of business continuity management. Lecture Notes in Electrical Engineering, 140, pp. 285-289, 2012.

[4] ] Zheng Jun, Wang Yining, Wang Kailing, \& Bai Yu The research of the design of micro video for learning (in Chinese) ］China Educational Technology, (2): 10 -13. 2012

[5]Wu Chuan-yu, He Lei-ying, Design and Realization of Instructional RPPR-Robot, Research and Exploration in Laboratory.2007, 26(10)

[6] Chen Gang, Research on workflow management model based on ontology in data center [C] 4th International Conference on Frontiers of Manufacturing and Design Science, ICFMD 2013 2045-2048

[7] GANG GHEN. Design teacher educational technique training policies based on teacher's personality characteristics in E-learning 2nd International Workshop on Education Technology and Computer Science, ETCS 2010 307-310 